\title{
QUALIDADE DE SEMENTES DE SOJA EM FUNÇÃO DO HORÁRIO DE COLHEITA E DO SISTEMA DE TRILHA DE FLUXO RADIAL E AXIAL
}

\section{MARIA C. MARCONDES ${ }^{1}$, ÉDISON MIGLIORANZA ${ }^{2}$, INÊS C. DE B. FONSECA ${ }^{3}$}

RESUMO: O trabalho objetivou avaliar dois tipos de colhedoras, de fluxo radial e axial, em relação à qualidade física e fisiológica de sementes de duas cultivares de soja, BRS 184 e BRS 133, colhidas em dois horários, às $10 \mathrm{e} 18$ horas. A colhedora de fluxo radial trabalhou a $5,0 \mathrm{~km} \mathrm{~h}^{-1}$, com o cilindro batedor a 750 rotações por minuto (rpm). A colhedora de fluxo axial trabalhou a 8,0 $\mathrm{km} \mathrm{h}^{-1}$, e rotor com $650 \mathrm{rpm}$. Para a avaliação da qualidade física e fisiológica das sementes, foram realizados testes de germinação, envelhecimento acelerado, tetrazólio, dano mecânico (hipoclorito), umidade de campo e laboratório, sementes quebradas (bandinha) e pureza. A colheita realizada às 18 horas, com grau de umidade menor que $12 \%$, ocasionou maiores danos mecânicos nas sementes da cultivar BRS 184. A colhedora de sistema de fluxo axial resultou em sementes de melhor qualidade fisiológica para a cultivar BRS 184, e em menores percentuais de sementes quebradas e maior pureza para ambas as cultivares, comparativamente à colhedora de sistema de trilha com fluxo radial.

PALAVRAS-CHAVE: Glycine max, qualidade, desempenho de colhedora.

\section{SOYBEAN SEEDS QUALITY IN FUNCTION OF THE HARVEST TIME AND THE RADIAL OR AXIAL ROTARY FLOW TRACK SYSTEM}

\begin{abstract}
This experiment aimed to evaluate two types of harvest combines, the radial flow and axial flow rotary, regarding the physical and physiological seed quality of BRS 184 and BRS 133 soybeans cultivars, harvested in two periods of the day, at 10 a.m. and 6 p.m. The conventional combine worked moving at $5.0 \mathrm{~km} \mathrm{~h}^{-1}$, cylinder speed at 750 rotations per minute (rpm). The axial rotary combine worked moving at $8.0 \mathrm{~km} \mathrm{~h}$, rotorspeed at $650 \mathrm{rpm}$. The germination test, vigour test, tetrazolium, mechanical (hypochlorite) damage, field and laboratory humidity test, broken seeds test and purity test were used to evaluate the physical and physiological quality of the seeds. The experiment performed at $6 \mathrm{pm}$, with a humidity level inferior to $12 \%$, presented greater mechanical damages in BRS 184 seeds. The axial flow rotary harvest presented better seed physiological quality for BRS 184 cultivar, less percentage of broken seeds and greater purity for both cultivars, comparatively to the results observed for the radial flow rotary harvest.
\end{abstract}

KEYWORDS: Glycine max, quality, harvest performance.

\footnotetext{
${ }^{1}$ Eng $^{\text {a }}$ Agrônoma, Secretaria de Estado da Agricultura e do Abastecimento, Av. Dr. Munhoz da Rocha, 51, Fone (0XX43) 3422.7822, Apucarana - PR, celeste@ seab.pr.gov.br.

${ }^{2}$ Eng $^{\mathrm{O}}$ Agrônomo, Prof. Adjunto, CCA/UEL, Departamento de Agronomia, Londrina - PR, emiglior@uel.br.

${ }^{3}$ Eng $^{\mathrm{a}}$ Agrônoma, Profa. Associada, CCA/UEL, Departamento de Agronomia, Londrina - PR, inescbf@uel.br.

Recebido pelo Conselho Editorial em: 29-7-2008

Aprovado pelo Conselho Editorial em: 21-2-2010
} 


\section{INTRODUÇÃO}

A qualidade da semente de soja, principalmente nas regiões tropicais, pode ser influenciada por diversos fatores, que ocorrem antes e durante a colheita e em todas as demais etapas da produção de sementes, como secagem, beneficiamento, armazenamento e transporte. Tais fatores abrangem, entre outras condições, períodos de seca, danos por insetos, extremos de temperatura durante a maturação e fortes flutuações das condições de umidade ambiental, facilitando o aparecimento de sementes com altos índices de deterioração por umidade (FRANÇA NETO et al., 2000).

A colheita constitui uma importante etapa no processo produtivo de soja, principalmente pelos riscos a que está sujeita a lavoura destinada à produção de sementes. Para evitar perdas na qualidade do produto, a colheita deve ser iniciada tão logo a soja atinja o estádio R8, correspondente ao ponto de maturação fisiológica, com o grau de umidade entre $13 \%$ e 15\%, onde se dá a minimização dos problemas de danos mecânicos e perdas na colheita (EMBRAPA, 2004). Sementes colhidas com grau de umidade superior a $15 \%$ estão sujeitas a maior incidência de danos mecânicos latentes, ou seja, ocultos, não perceptíveis e, quando colhidas com grau abaixo de $12 \%$, estão suscetíveis ao dano mecânico imediato, ou seja, a quebra (COSTA et al., 1979; FRANÇA NETO \& HENNING, 1984).

No horário de colheita das 18 horas, sementes colhidas com grau de umidade inferior ao percentual de $12 \%$, para a cultivar BRS 184, não apresentaram diferenças nas percentagens de danos mecânicos, conforme constatado por MARCONDES et al. (2005). Ainda segundo esses autores, a colhedora com fluxo radial, deslocando-se a $5,0 \mathrm{~km} \mathrm{~h}^{-1}$ e a axial a $8,0 \mathrm{~km} \mathrm{~h}^{-1}$, mostrou resultados que não diferiram estatisticamente entre si. Em trabalho realizado com colhedoras de fluxo radial, independentemente da regulagem, foram constatadas diferenças físicas e fisiológicas nas sementes de soja quando estas foram colhidas com umidade de 10,8\% (COSTA et al., 1996). Estes autores ressaltam, ainda, que a velocidade média da colhedora de $4,5 \mathrm{~km} \cdot \mathrm{h}^{-1}$ tem sido usada normalmente para a colheita de sementes de soja.

Os danos na semente causados pelo impacto das partes do sistema de corte da colhedora na debulha e pela folga incorreta entre sistema estacionário e movimento das partes da máquina, sob alta velocidade, provocam aumento no número de sementes danificadas (UKATU, 2006).

Rotações do cilindro de trilha inferiores a $500 \mathrm{rpm}$ promovem menores índices de danos mecânicos à semente, ocorrendo redução nos índices de quebras, rupturas do tegumento e, consequentemente, uma superioridade em valores absolutos com ganhos de germinação, vigor e viabilidade, resultando em melhor qualidade fisiológica das sementes (COSTA et al., 2001). Velocidades de operação na faixa de 4,0 a $5,0 \mathrm{~km} \mathrm{~h}^{-1}$ resultam em menores índices de perdas na colheita e, consequentemente, menores danos mecânicos e declínio no vigor (HERBEK \& BITZER, 1997).

O sistema de trilha na colheita de soja provoca quebra de pequenos fragmentos nos grãos e que, muitas vezes, esses danos não são percebidos nos restos culturais ou em medições de perdas, conforme afirmam MESQUITA et al. (1998). As perdas com a quebra dos grãos representam de $1,7 \%$ a $14,5 \%$ das perdas na colheita, e as colhedoras que possuem sistema de fluxo axial, apresentam menos danos mecânicos às sementes quando comparadas com sistema de fluxo radial (MESQUITA et al., 2002).

Comercialmente, encontram-se, para colheita mecânica de soja, colhedoras com sistema de debulha de fluxo radial e de fluxo axial, que podem produzir efeitos diferenciados na qualidade fisiológica de sementes (MARCOS \& MIELII, 2005).

Considerando-se a seriedade com que deve ser tratado o processo de produção de sementes no tocante às injúrias mecânicas com relação à qualidade física e fisiológica de sementes de soja, objetivou-se, com este trabalho, avaliar colhedoras com sistema de trilha de fluxo radial e axial em horários de colheita diferenciados. 


\section{MATERIAL E MÉTODOS}

O trabalho foi conduzido no município de Marilândia do Sul - PR, latitude $23^{\circ} 16^{\prime} 00^{\prime \prime}$ sul e longitude $51^{\circ} 18^{\prime} 00^{\prime \prime} \mathrm{W}$, altitude de $780 \mathrm{~m}$, na safra de 2004/2005, em áreas de produção de sementes, categoria S1(semente da classe não certificada), com as cultivares BRS 184 e BRS 133. Durante a operação de colheita, em seis dias consecutivos, foi amostrada a cultivar BRS 184, e, nos cinco dias subsequentes, a cultivar BRS 133, em dois horários diários, 10 horas e 18 horas, sendo estes horários estabelecidos por corresponder ao horário de início e término do processo de colheita, apresentando, respectivamente, umidades que variaram de $14,50 \%$ a $11 \%$ a cultivar BRS 184 e $16,50 \%$ e $10 \%$ a cultivar BRS 133.

Trabalhou-se com dois tipos de colhedoras, com regulagens rotineiras utilizadas na propriedade, durante a operação de colheita:

- Colhedora com sistema de trilha de fluxo radial - velocidade de deslocamento a 5,0 $\mathrm{km} \mathrm{h}^{-1}$ com velocidade periférica do molinete girando em velocidade $5 \%$ superior à da colhedora, cilindro de trilha com $750 \mathrm{rpm}$, com abertura de $10 \mathrm{~mm}$ de entrada e $10 \mathrm{~mm}$ de saída;

- Colhedora com sistema de trilha de fluxo axial - deslocamento a $8,0 \mathrm{~km} \mathrm{~h}^{-1}$ com velocidade periférica do molinete girando em velocidade $10 \%$ superior à da colhedora, rotor com $650 \mathrm{rpm}$, abertura do côncavo 3 a 4 na escala da colhedora, ventilador com $1.050 \mathrm{rpm}$ na peneira para limpeza da semente.

Foi utilizado o delineamento em blocos ao acaso, com seis repetições para a cultivar BRS 184 (24 parcelas), e cinco repetições para a cultivar BRS 133 (20 parcelas), em esquema fatorial 2x2 (máquina $\mathrm{X}$ hora de colheita), totalizando quatro tratamentos para cada cultivar. A área de cada parcela foi de $2.400 \mathrm{~m}^{2}$ (40 $\mathrm{m}$ de largura por $60 \mathrm{~m}$ de comprimento).

\section{Avaliações realizadas}

Amostragem de sementes no campo - para a avaliação da qualidade física e fisiológica, foram coletadas amostras com $2 \mathrm{~kg}$ de sementes do tanque graneleiro das colhedoras, nos dois horários, para cada bloco (dia), para ambas as cultivares. Todas as amostras foram acondicionadas em sacos de papel multifoliado, identificadas e armazenadas. Dole 400.

Determinação do grau de umidade no campo (\%) - foi obtida com o equipamento da marca

As análises de pureza, germinação, vigor, tetrazólio (viabilidade e danos mecânicos), umidade e sementes quebradas (bandinhas) foram realizadas em Laboratório Oficial da CLASPAR Empresa de Classificação do Paraná, Maringá - PR, conforme metodologias descritas a seguir:

Teste de germinação (\%) - foi realizado utilizando-se de 400 sementes, distribuídas em oito repetições de 50 sementes, semeadas em rolo de papel-toalha tipo "Germitest" umedecido com água destilada na proporção de 2,5 vezes o seu peso, e colocadas em germinador sob temperatura constante de $25^{\circ} \mathrm{C}$, sendo as avaliações realizadas aos 4 e 8 dias, computando-se a porcentagem de plântulas normais, conforme as recomendações das Regras para Análise de Sementes (BRASIL, 1992).

Envelhecimento acelerado - E.A. (\%) - foram utilizadas 400 sementes por tratamento, distribuídas em oito repetições de 50 sementes e acondicionadas sobre tela dentro de caixas plásticas, tipo gerbox, contendo $40 \mathrm{~mL}$ de água destilada. Devidamente tampadas, as caixas foram colocadas em estufa incubadora, tipo BOD, a $42{ }^{\circ} \mathrm{C}$ por 48 horas (KRIZYZANOWSKI et al., 1991). Após o envelhecimento, as sementes foram colocadas para germinar, seguindo a mesma metodologia adotada no teste de germinação, calculando-se a percentagem de plântulas normais.

Teste de tetrazólio (\%) - foi conduzido com 400 sementes de cada cultivar, as quais ficaram pré-condicionadas em papel Germitest umedecido, com quantidade de água equivalente a 2,5 vezes o seu peso, durante 16 horas, em temperatura ambiente. Passado este período, as sementes foram 
colocadas em copos de Becker, contendo solução com concentração de 0,075 \% de 2,3,3-trifenilcloreto de tetrazólio, e, em seguida, foram colocadas no escuro, em estufa, com temperatura entre 35 e $40^{\circ} \mathrm{C}$, por três horas, para o desenvolvimento da coloração. Após a lavagem em água corrente, as sementes foram analisadas individualmente, verificando-se a percentagem de viabilidade e de danos mecânicos (FRANÇA NETO et al., 1998).

Teste de hipoclorito de sódio (\%) - misturaram-se $25 \mathrm{~mL}$ de solução de hipoclorito de sódio a $5,25 \%$ em um litro de água potável. Foram contadas quatro repetições de 100 sementes inteiras (excluindo-se as sementes partidas e as quebradas), que foram colocadas na bandeja gerbox. A seguir, a solução já preparada de hipoclorito foi adicionada até cobrir toda a semente. Após 15 minutos, a solução de hipoclorito foi escorrida, e a semente foi colocada em papel-toalha para averiguação do número de sementes que embeberam a solução, calculando-se o percentual de danos mecânicos pela média das repetições.

Grau de umidade no laboratório (\%) - foi determinado pelo Método Expedito, com aparelho Universal.

Sementes quebradas - (bandinhas) e pureza (\%) - para a determinação de sementes quebradas ou bandinhas (sementes partidas, divididas em seus cotilédones), e pureza, foram utilizados $2 \mathrm{~kg}$ de sementes provenientes de cada amostragem. Foi empregada uma sequência de peneiras de crivo oblongas, número 11/64 x 3/4, sendo a avaliação das sementes quebradas obtida pela razão entre a massa das mesmas e a massa total da respectiva amostra em percentagem.

Os dados foram submetidos à análise de variância, e as médias comparadas pelo teste de Tukey, a 5\% de probabilidade, independentemente para cada cultivar.

\section{RESULTADOS E DISCUSSÃO}

Não houve interação $(P>0,05)$ entre os fatores avaliados, quais sejam, horários de colheita e sistemas de trilha de fluxo radial e axial; por esta razão, os resultados foram apresentados isoladamente (Tabelas 1 e 2).

Observa-se pelos resultados que sementes da cultivar BRS 184, colhidas no horário das 10 horas com umidade superior a $15 \%$ apresentaram danos mecânicos $(\mathrm{P} \leq 0,05)$, detectados pelo teste de hipoclorito de sódio, menores do que as sementes colhidas no horário das 18 horas com umidade abaixo de $12 \%$ (Tabela 1 ).

TABELA 1. Qualidade física e fisiológica de sementes de soja colhidas nos horários das 10 horas e 18 horas, em Marilândia do Sul - PR na safra de 2004/2005. Physical and physiological traits of soybean seeds harvested at 10:00 AM and 6:00 PM in Marilândia do Sul, PR. Harvest season: 2004/2005.

\begin{tabular}{lrrrrrr}
\hline \multirow{2}{*}{ Avaliações } & \multicolumn{3}{c}{ BRS 184 } & \multicolumn{3}{c}{ BRS 133 } \\
\cline { 2 - 7 } & C.V.\% & \multicolumn{1}{c}{$10 \mathrm{~h}$} & $18 \mathrm{~h}$ & $\mathrm{C} . \mathrm{V} . \%$ & \multicolumn{1}{c}{$10 \mathrm{~h}$} & $18 \mathrm{~h}$ \\
\hline Umidade de campo (\%) & 4,36 & $15,77 \mathrm{~A}^{(1)}$ & $11,70 \mathrm{~B}$ & 4,21 & $15,87 \mathrm{~A}$ & $11,69 \mathrm{~B}$ \\
Germinação (\%) & 2,31 & $95,42 \mathrm{~A}$ & $94,25 \mathrm{~A}$ & 2,50 & $92,30 \mathrm{~A}$ & $92,80 \mathrm{~A}$ \\
Envelhecimento acelerado (\%) & 2,80 & $93,42 \mathrm{~A}$ & $92,75 \mathrm{~A}$ & 2,95 & $87,70 \mathrm{~B}$ & $90,50 \mathrm{~A}$ \\
Tetrazólio (\%) & 2,28 & $94,08 \mathrm{~A}$ & $93,58 \mathrm{~A}$ & 4,01 & $92,20 \mathrm{~A}$ & $94,60 \mathrm{~A}$ \\
Dano mecânico* (viáveis) & 26,34 & $1,42 \mathrm{~A}$ & $2,00 \mathrm{~A}$ & 25,92 & $1,20 \mathrm{~A}$ & $1,00 \mathrm{~A}$ \\
Dano mecânico* (não viáveis) & 23,85 & $3,50 \mathrm{~A}$ & $3,83 \mathrm{~A}$ & 29,77 & $2,80 \mathrm{~A}$ & $2,80 \mathrm{~A}$ \\
Dano mecânico* (hipoclorito) & 17,62 & $12,25 \mathrm{~B}$ & $16,92 \mathrm{~A}$ & 15,05 & $12,70 \mathrm{~A}$ & $14,50 \mathrm{~A}$ \\
Umidade laboratório (\%) & 2,53 & $11,40 \mathrm{~A}$ & $11,35 \mathrm{~A}$ & 3,24 & $11,82 \mathrm{~A}$ & $11,59 \mathrm{~A}$ \\
Semente quebrada (\%) & 25,00 & $3,54 \mathrm{~A}$ & $4,33 \mathrm{~A}$ & 33,38 & $2,67 \mathrm{~A}$ & $3,63 \mathrm{~A}$ \\
Pureza (\%) & 2,83 & $95,51 \mathrm{~A}$ & $94,44 \mathrm{~A}$ & 3,73 & $95,00 \mathrm{~A}$ & $93,13 \mathrm{~A}$ \\
\hline (1) Médias seguidas de mesma letra na linha não diferem entre si, pelo teste de Tukey (p<0,05). & & \\
*Os dados de dano foram transformados em arc-seno x/100 para análise estatística. & \multicolumn{3}{c}{}
\end{tabular}


TABELA 2. Qualidade física e fisiológica de sementes de soja colhidas com colhedora com sistema de trilha de fluxo radial e fluxo axial, em Marilândia do Sul-PR, na safra de 2004/2005. Physical and physiological traits of soybean seeds harvested by the conventional and axial flow harvest combines in Marilândia do Sul, PR. Harvest season: $2004 / 2005$.

\begin{tabular}{lrrrrrr}
\hline \multirow{2}{*}{ Avaliações } & \multicolumn{3}{c}{ BRS 184 } & \multicolumn{3}{c}{ BRS 133 } \\
\cline { 2 - 6 } & C.V.\% & \multicolumn{1}{c}{ Radial } & \multicolumn{1}{c}{ Axial } & C.V.\% & Radial & \multicolumn{1}{c}{ Axial } \\
\hline Umidade de campo (\%) & 4,36 & $13,77 \mathrm{~A}^{(1)}$ & $13,70 \mathrm{~A}$ & 4,21 & $13,90 \mathrm{~A}$ & $13,66 \mathrm{~A}$ \\
Germinação (\%) & 2,31 & $93,42 \mathrm{~B}$ & $96,25 \mathrm{~A}$ & 2,50 & $92,10 \mathrm{~A}$ & $93,00 \mathrm{~A}$ \\
Envelhecimento acelerado (\%) & 2,80 & $91,42 \mathrm{~B}$ & $94,75 \mathrm{~A}$ & 2,95 & $90,10 \mathrm{~A}$ & $88,10 \mathrm{~A}$ \\
Tetrazólio (\%) & 2,28 & $92,33 \mathrm{~B}$ & $95,33 \mathrm{~A}$ & 4,01 & $93,70 \mathrm{~A}$ & $93,10 \mathrm{~A}$ \\
Dano mecânico* (viáveis) (\%) & 26,34 & $2,25 \mathrm{~A}$ & $1,17 \mathrm{~B}$ & 25,92 & $1,10 \mathrm{~A}$ & $1,10 \mathrm{~A}$ \\
Dano mecânico* (não viáveis) (\%) & 23,85 & $4,58 \mathrm{~A}$ & $2,75 \mathrm{~B}$ & 29,77 & $3,60 \mathrm{~A}$ & $2,00 \mathrm{~A}$ \\
Dano mecânico* (hipoclorito) (\%) & 17,62 & $17,92 \mathrm{~A}$ & $11,25 \mathrm{~B}$ & 15,05 & $14,70 \mathrm{~A}$ & $12,50 \mathrm{~A}$ \\
Umidade laboratório (\%) & 2,53 & $11,41 \mathrm{~A}$ & $11,35 \mathrm{~A}$ & 3,24 & $11,63 \mathrm{~A}$ & $11,78 \mathrm{~A}$ \\
Semente quebrada (\%) & 25,00 & $6,43 \mathrm{~A}$ & $1,44 \mathrm{~B}$ & 33,38 & $4,90 \mathrm{~A}$ & $1,40 \mathrm{~B}$ \\
Pureza (\%) & 2,83 & $92,22 \mathrm{~B}$ & $97,73 \mathrm{~A}$ & 3,73 & $91,58 \mathrm{~B}$ & $96,55 \mathrm{~A}$ \\
\hline (1) Médias seguidas de mesma letra na linha não diferem entre si, pelo teste de Tukey (p<0,05). & &
\end{tabular}

A cultivar BRS 133, que também apresentou variações estatísticas para o grau de umidade entre os dois horários de colheita, apresentou menor vigor $(\mathrm{P} \leq 0,05)$, avaliados pelo teste de envelhecimento acelerado, nas sementes com maior grau de umidade colhidas no horário das 10 horas. Existe citação de efeitos negativos da colheita com grau de umidade abaixo de 12\%, conforme constatado por COSTA et al., (1979) e FRANÇA NETO \& HENNING (1984), que umidades de sementes inferiores a $12 \%$, durante o processo de colheita, podem apresentar efeitos negativos no tocante a danos mecânicos. Parâmetros desejáveis para a umidade da semente durante a fase de colheita da cultura da soja, onde os danos mecânicos são reduzidos, são na faixa de umidade entre $15 \%$ e $13 \%$, apresentando maiores índices de vigor e viabilidade (EMBRAPA, 2004).

Quando comparados os dois sistemas de trilha, o de fluxo radial com o de fluxo axial (Tabela 2), verificam-se diferenças estatísticas superiores para a colhedora de fluxo axial. A cultivar BRS 184 apresentou $(\mathrm{P} \leq 0,05)$ percentuais superiores de germinação, viabilidade pelo teste de tetrazólio e vigor, e inferiores de danos mecânicos (viáveis e não viáveis) pelo teste de tetrazólio e de hipoclorito de sódio, demonstrando a superioridade da colhedora de fluxo axial, em relação à qualidade de sementes. Porém, na cultivar BRS 133, estes resultados não foram constatados $(\mathrm{P}>0,05)$ devido à diferença de comportamento entre as duas cultivares amostradas, que consideram que esse é um atributo importante a ser observado, pois existem diferenças genéticas entre as várias cultivares disponíveis no mercado (COSTA et al., 1996). As partes embrionárias da semente de soja são compostas de um tegumento pouco espesso que lhe confere baixa proteção contra choques e abrasões que se verificam durante a colheita mecânica, comprometendo, na maioria das vezes, a qualidade fisiológica da semente, conforme enfatizam FRANÇA NETO \& HENNING (1984).

Embora não tenham sido utilizadas as combinações de velocidade de operação $(3,5 ; 4,5$ e $5,5 \mathrm{~km} \mathrm{~h}^{-1}$ ) e rotações do cilindro de trilha (400 e $500 \mathrm{rpm}$ ), conforme especificam VIEIRA et al. (2006), como adequadas para não afetar variáveis de impurezas e sementes quebradas (bandinhas), em ambas as cultivares, BRS 184 e BRS 133, mesmo com velocidades de deslocamento das colhedoras acima, a de fluxo radial, deslocando-se a $5,0 \mathrm{~km} \mathrm{~h}^{-1}$,e a de fluxo axial a $8,0 \mathrm{~km} \mathrm{~h}^{-1}$, os valores avaliados foram superiores para a colhedora de fluxo axial, apresentando diferenças estatisticas significativas, conforme dados da Tabela 2. A colheita realizada com maiores rotações do cilindro de trilha resulta em níveis mais acentuados de danos mecânicos, sementes quebradas e ruptura de tegumento, principalmente quando associada a maiores índices de deterioração por 
umidade, lesões por percevejo e teor de água das sementes no momento da colheita (COSTA et al., 2002). Constatou-se que não houve diferenças significativas entre as perdas de grãos e entre as rotações do cilindro em função da velocidade de avanço das colhedoras que foram de $6,33 \mathrm{~km} \mathrm{~h}^{-1}$ para sistema de trilha com fluxo axial e $6,84 \mathrm{~km} \mathrm{~h}^{-1}$ para sistema de trilha com fluxo radial (CAMPOS et al., 2005). Não foram constatadas diferenças estatísticas nas amostras colhidas nos sistemas de fluxo axial com deslocamento a $8,0 \mathrm{~km} \mathrm{~h}^{-1}$, com velocidade periférica do molinete girando em velocidade $10 \%$ superior à da colhedora, rotor com $650 \mathrm{rpm}$, e na colhedora com sistema de trilha com fluxo radial, deslocamento a $5,0 \mathrm{~km} \mathrm{~h}^{-1}$, cilindro trilhador com $750 \mathrm{rpm}$ em trabalho realizado por MARCONDES et al., (2005).

Os valores evidenciados de danos e sementes quebradas, inferiores na colhedora de fluxo axial, corroboram MACHADO (2007), que relata que o grau de danificação da semente se reduz sensivelmente, quando se utilizam máquinas equipadas com o sistema de trilha de fluxo axial, devido ao maior período de tempo que o material permanece na seção de trilha, bem como devido a essa trilha não ser tão agressiva quanto a que ocorre no sistema de fluxo radial, o que caracteriza a indicação para a colheita de sementes de soja ou de grãos mais sensíveis a danificações mecânicas. O sistema de trilha na colheita de soja provoca quebra de pequenos fragmentos nos grãos e que, muitas vezes, esses danos não são percebidos nos restos culturais ou em medições de perdas, conforme citam MESQUITA et al. (1998, 2002). Colhedoras que possuem sistema de trilha de fluxo axial apresentam menos danos mecânicos às sementes quando comparadas com sistema de trilha de fluxo radial, conforme relatam MARCOS \& MIELLI (2005), que o padrão diagonal e laminas no ventilador de fluxo cruzado "Cross Flow" requerem menos potência, ao mesmo tempo em que criam um grande fluxo de ar distribuído uniformemente na largura das peneiras, resultando em grãos mais limpos e com menos impurezas.

\section{CONCLUSÕES}

A colheita realizada às 18 horas, com grau de umidade menor que $12 \%$, ocasionou maiores danos mecânicos nas sementes da cultivar BRS 184.

A colheita realizada pela colhedora de sistema de fluxo axial resultou em sementes de melhor qualidade fisiológica para a cultivar BRS 184, e em menores percentuais de sementes quebradas - bandinha e maior pureza para ambas as cultivares, comparativamente à colhedora de sistema de trilha de fluxo radial.

\section{AGRADECIMENTOS}

A Lino Favoreto e Filhos - Sementes Eldorado, por propiciar as condições necessárias para a execução deste trabalho.

\section{REFERÊNCIAS}

BRASIL. Ministério da Agricultura e da Reforma Agrária. Regras para análise de sementes. Brasília, 1992. 365 p.

CAMPOS, M.A.O.; SILVA, R.P.; CARVALHO, A.F.; MESQUITA, H.C.B.; ZABANI, S. Perdas na colheita mecanizada de soja no Estado de Minas Gerais. Engenharia Agrícola, Jaboticabal, v.25, n.1, p.207-213, 2005.

COSTA, N.P.; MESQUITA, C.M.; HENNING, A.A. Avaliação das perdas e qualidade de semente na colheita mecânica da soja. Revista Brasileira de Sementes, Pelotas, v.1, n.3, p.59-70, 1979.

COSTA, N.P.; MESQUITA, C.M.; MAURINA, A.C; FRANÇA NETO, J.B.; PEREIRA, J.E.; BORDINGNON, J.R., KRZYZANOWSKI, F.C.; HENNING, A.A. Efeito da colheita mecânica da soja nas características físicas, fisiológicas e químicas das sementes em três Estados do Brasil. Revista Brasileira de Sementes, Pelotas, v.23, n1, p.144-145, 2001. 
COSTA, N.P.; MESQUITA, C.M.; OLIVEIRA, M.C. Efeito da velocidade de deslocamento e do cilindro de trilha da colhedora sobre as perdas de sementes na colheita de soja. Informativo Abrates, Londrina, v.12, n.1-3, p.15-19, 2002.

COSTA, N.P.; OLIVEIRA, M.C.N.; HENNING, A.A.; KRZYZANOWSKI, F.C.; MESQUITA, C.M.; TAVARES, L.C.V. Efeito da colheita mecânica sobre a qualidade de semente de soja. Revista Brasileira de Sementes, Pelotas, v.18, n.2, p.232-237, 1996.

EMBRAPA. EMPRESA BRASILEIRA DE PESQUISA AGROPECUÁRIA. Tecnologias de produção de soja - Paraná 2005. Londrina: Embrapa Soja, 2004. 224 p.

FRANÇA NETO, J.B.; HENNING, A.A. Qualidade fisiológica da semente. Londrina: EMBRAPACNPSo, 1984. p.5-24. (Circular Técnica, 9)

FRANÇA NETO, J.B.; KRZYZANIWSKI, F.C.; COSTA, N.P. O teste de tetrazólio em sementes de soja. Londrina: EMBRAPA-CNPSo, 1998. 72 p. (Documento, 116)

FRANÇA NETO, J.B.; KRZYZANIWSKI, F.C.; HENNING, A.A.; COSTA, N.P. Tecnologia de produção de semente. In: EMBRAPA SOJA. A cultura da soja no Brasil. Londrina, 2000. 1 CDROM.

HERBEK, J.H.; BITZER. M.J. Soybean production in Kentucky: harvesting, drying, storage and marketing. Lexington: University of Kentucky, College of Agriculture, 1997. part.5, p.1-5.

KRZYZANOWSKI, F.C.; FRANÇA NETO, J.B.; HENNING, A.A. Relato dos testes de vigor disponíveis para grandes culturas. Informativo ABRATES, Londrina, v.1, n.2, p.15-37, 1991.

MACHADO, A.L.T. Colhedoras de fluxo axial reduzem danos às sementes. Disponível em: <www.seednews.inf.br/portugues/seed74/artigocapa74.shtml>. Acesso em: 10 nov. 2007.

MARCONDES, M.C.; MIGLIORANZA, É.; FONSECA, I.C.B. Danos mecânicos e qualidade fisiológica de semente de soja colhida pelo sistema convencional e axial. Revista Brasileira de Sementes, Pelotas, v.27, n.2, p.125-129, 2005.

MARCOS, S.; MIELII, U. Axial-Flow, a mais nova campeã de produtividade. Disponível em <www.sppress.net/E-Foco>. Acesso em: 26 jun. 2005.

MESQUITA, C.M.; COSTA, N.P.; OEREURA, J.E.; MAURINA, A.C.; ANDRADE, J.G.M. Perfil da colheita mecânica de soja no Brasil: safra 1998/1999. Engenharia Agrícola, Jaboticabal, v.22, n.3, p.398-406, 2002.

MESQUITA, C.M.; MOLIN, J.P.; COSTA, N.P. Avaliação preliminar de perdas "invisíveis" na colheita da soja. In: CONGRESSO BRASILEIRO DE ENGENHARIA AGRICOLA, 27., 1998, Poços de Caldas. Anais... Lavras: Sociedade Brasileira de Engenharia Agrícola, 1998. p.106-108.

UKATU, A.C. A modified threshing unit for soybeans. Biosystems Engineering, London, v.95, n.3, p.371-377, 2006.

VIEIRA, B.G.T.L.; SILVA, R.P.; VIEIRA, R.D. Qualidade física e fisiológica de semente de soja colhida com sistema de trilha axial sob diferentes velocidades de operação e rotações do cilindro trilhador. Engenharia Agrícola, Jaboticabal, v.26, p.478-482, 2006. 